Vol. 3, No. 2, 2017

\author{
Volodymyr Biloborodchenko ${ }^{1}$, Andrii Dzyubyk ${ }^{2}$, Andrii Zabranskyi ${ }^{3}$ \\ ${ }^{1}$ Department of Welding Manufacture, Diagnostics and Restoration of Metal Structures, Lviv Polytechnic \\ National University, 12, S. Bandery Str., Lviv, Ukraine, E-mail: vbilko22@ gmail.com \\ ${ }^{2}$ Department of Welding Manufacture, Diagnostics and Restoration of Metal Structures, Lviv Polytechnic \\ National University, 12, S. Bandery Str., Lviv, Ukraine, E-mail: dar.lviv@ gmail.com \\ ${ }^{3}$ Department of Welding Manufacture, Diagnostics and Restoration of Metal Structures, Lviv Polytechnic \\ National University, 12, S. Bandery Str., Ukraine, Lviv, E-mail: zvdv@ukr.net
}

\title{
INVESTIGATION OF MAGNETICALLY CONTROLLED ELECTRIC ARC
}

\author{
Received: September 15, 2017 / Revised: November 22, 2017 / Accepted: December 26, 2017
}

\section{C) Biloborodchenko V., Dzyubyk A., Zabranskyi A., 2017}

Abstract. In this work, the results of pad welding with the circularly rotating arc existing in an inert gas between a circle cathode with the diameter suitable to dimensions and geometry of a welded surface, with the kinematic characteristics of the motion provided (with the rest equal conditions) by the external magnetic field, are considered.

It is shown that the strict theory of an electric arc is insufficient for the description of real physical processes occurred in it under the action of external exciting magnetic fields, and so it does not allow conducting satisfactory technological calculations of the parameters of the pad welding process performed by the arc moved by the external magnetic field. The main problem consists in determining the effectiveness and the direction of superposition of electrodynamic and mechanical forces in it, which resist arc interaction with the magnetic field.

Therefore, the aim of the work is to investigate the influence of the induction value $B$ of the transvers magnetic field of a solenoid inductor on predicted kinematic characteristics of the arc.

The investigations were conducted with the use of experimental equipment (test bench) consisting of a toroidal inductor with a winding. On the inductor, a nonfusible water-cooled ring copper electrode is mounted. Electrode dimensions agree with the diameter of pad surface. The shielding gas is provided through the system of radially located nozzles with discreet valvular operation, whose work priority is agreed with the arc motion velocity by a control unit. Since the values of abovementioned forces directly conditioned by the presence of a magnetic field in an interelectrode gap, the investigation of its intensity by the electrodynamic method with the help of the measuring instrument for magnetic induction ИМИ-1 was carried out.

The analysis of the superimposed surface of the impact of the magnetizing current and the arc gap, which are used at pad welding by magnetically controlled arc, on the field induction shows that the range of their influence as technological mode parameters is quite narrow. Accordingly, for optimal choice of model nomographic solutions and the description of the correlation of parameters of the arc gap and magnetizing current, which provide the technologically suitable induction, an experiment was conducted according to the matrix of simplex-summarized $\mathrm{C}-\mathrm{C}_{2}$ design. The investigations of a model extremum shows the acceptable induction value of $850 \cdot 10^{-5} \mathrm{~T}$ for the length of the electrode gap of $4 \mathrm{~mm}$ and inductor magnetizing current of $6 \mathrm{~A}$.

As a result, the proposed design of the test bench satisfies the geometrical parameters of renovated workpiece and enables using the effective repeated thermal pad cycle per unit of the surface by the rotating arc in the stable magnetic field. Settings of the magnetically operated arc, which provide the necessary value of field induction in the inter-electrode gap, can be determined either by nomograph solution, or by the strict statistic models. The influence of the length of the inter-electrode gap on the choice of the induction value is limited by technologically suitable pad current and corresponding length of an arc column. The main setting and controlling parameter of 
the magnetic field mode is the inductor magnetizing current. The force of resistance to arc motion at the stage of arc development and at the stage of arc steady motion is directly proportional to the value of the pad current. Calculated values of the velocity of arc motion at given values of the pad current are in the range relevant to its steady motion and provide the processes of anode melting without thermal damaging the ring cathode.

Keywords: pad welding; circularly rotating arc; inert gas; magnetic field; induction; interelectrode gap; pad current; anode melting; magnetizing current.

\section{Introduction and Problem Statement}

The interaction of the current flowing through the ionized gas-dynamic conductor, which can be, for example, the welding arc, with externally controlled magnetic field is quite widely used in different branches of industry, for example, in electrometallurgy (rotating arc between carbon electrodes), power electronics (superpower gas control valves - the arc with a rotating cathode spot), welding technologies [1]-[4]. For welding, two approaches are mainly adopted: a) arc motion with fixed cathode spot location on the electrode; b) arc motion along a certain trajectory, controlled with the external magnetic field and simultaneous unsteady location of cathode and anode spots [4]-[6].

Optimal results can be obtained by pad welding with arc circular rotation existing in inert gas between the nonfusible circle cathode with the diameter suitable to the dimensions and geometry of welded surface, with the given kinematic characteristics of the motion, which are determined, with the rest equal conditions, by the externally controlled magnetic field. Accordingly, such a repeated thermal deformation cycle of the arc effect on the unit of heated surface will have positive influence on the level of residual stress after padding and allow obtaining pre-set metallurgical and structural transformations in the padded layer, which meet operational requirements for a workpiece.

Moreover, the attention should be paid to the presence of magneto-sensitive components in the padded layer, which can make better / worse the dynamical conditions for arc interaction with the magnetic field and influence final forming of the structure of the padded layer.

Arc mobility and conditions of its interacting with the magnetic field somehow limit the effective applying of classical techniques of pad welding by the nonfusible electrode, such as the introduction of adding material in the form of powder mixtures or solid wires into the arc gap or placing disperced particles of pad material on the workpiece surface $[5 ; 6]$.

\section{Review of Modern Information Sources on the Subject of the Paper}

The most appropriate solution for the task of padding with the rotating arc controlled by the external magnetic field consists in the prior location of continuous layer of pad material formed according to the given geometry of surface being restored [7]-[10].

It is shown that the strict theory of an electric arc [6] is insufficient for the description of real physical processes occurred in it under the action of external exciting magnetic fields, and so it does not allow conducting satisfactory technological calculations of the parameters of the pad welding process performed by the arc moved by the external magnetic field. The main problem consists in determining the effectiveness and the direction of superposition of electrodynamic and mechanical forces in it, which resist arc interaction with the magnetic field.

Roughly, the action of the transvers magnetic field on the arc can be considered to be applied to the whole set of charge carriers of arc current, despite their rearrangement and concentration in underelectrode zones of the arc column and the processes of their re-combination. The objective factor of such action is the change of arc geometry $[1-5 ; 6 ; 9 ; 10]$.

\section{Objectives and Problems of Research}

The aim of the study consisted in the investigation of the influence of the induction value $\mathrm{B}$ of the transvers component of magnetic field of the solenoid inductor on the predicted kinematic arc characteristics. 


\section{Main Material Presentation}

The investigations were conducted on the test bench (Fig. 1), consisting of the toroid inductor (1) with the winding (2). On the inductor, the nonfusible water-cooled ring copper electrode is mounted (3). Electrode dimensions agree with the diameter of pad surface (4). Shielding gas is provided into the interelectrode gap through the system of radially located nozzles with discreet valvular operation (not shown in Fig.1), whose work priority is agreed with the arc motion velocity by a control unit. For some particular renovated workpieces, the use of pad welding chambers with argon environment can be also allowed. The inductor is fed by a direct current (dc) power supply.

According to technological design for restoration of ring surfaces, the underhand weld padding is provided with the workpiece located under the inductor with the ring electrode and arc feeding by the dc power source. This variant fully meets the law of interacting the dc conductor with a steady magnetic field. Therefore, the interaction of the vector of padding current $I$ with the normal vector of induction $B$ causes the generation of a mechanical force being equivalent to the electromagnetic force $F_{l}$. This force stimulates circular arc motion and its pulse (for the unit of workpiece surface) thermal effect on pad material.

The arc motion velocity in the transvers magnetic field under normal pressure conditions (0.1 MPa) depends on the pad current value $I$, power of magnetic field $W$ in the ring gap, stability of the arc with the length of $L$, the electrode geometry (cathode and workpiece) etc.

Here, under other equal conditions, three kinds of spot kinematics can be noticed. At the motion velocity of $V \leq 23 \mathrm{~m} / \mathrm{sec}$, the arc motion is uneven; on the cathode (copper ring), the slight surface submeltings can be noticed in the places when the cathode spot has delayed; on the anode (workpiece), there is no noticeable changes of the padded surface. Within the velocity range $25 \leq V \leq 47 \mathrm{~m} / \mathrm{sec}$, the arc deformation is definitely noticed with a bend directing forward (in the direction of its motion) due to the inertia of dynamic electrode spots; workpiece surface melting depends on the time of the existence of the rotating arc. At higher velocities, a stable plasma ring along the whole length of the ring gap occurs, but unwanted melting of the ring cathode electrode takes place.

The velocity of arc motion is affected, under other equal conditions, by the processes of forming the dynamic cathode spot, which are conditioned by the thermal emissivity of cathode material, its ability to create oxide films, their conductivity and ability to dissipate, as well as electrode temperature. If a stable and relatively low-conductive film occurs, it slows down the appearance of the moving cathode spot. Only after the total destruction of an oxide layer and creation of metal conductivity, the arc achieves the velocity limited by the resistance of a gas in which it exists and by the inertia of ionization in the arc column. Therefore, the objective necessity of camera protection of padded zone occurs, since the discreet local gas protection of the arc promotes repeated creation and destruction of the film on the cathode. The intense thermo-emissive destruction of the cathode film by changing the arc current is limited by the requirements of pad welding technological modes.

The main peculiarity of pad surface heating by the arc moved by the magnetic field is the fact that the velocity of its motion is higher than the speed of welding the surface unit and, so, many-cycled thermal influence on the workpiece surface occurs, which allows providing its preset operational parameters.

Arc motion at any time point depends on the superposition of the electro-dynamic force and the complex of resistance forces. The former is:

$$
F_{1}=\alpha \cdot B \cdot I \cdot L
$$

where $\alpha$ is a dimension index.

At axial arc and radial magnetic field, the force $F_{1}$ at any time point is directed along a tangent line to the moving line of ring surface, which promotes the arc motion along the circle trajectory. The resistance forces, according to the principles of relativity of object motion or environment motion by the rules of flow dynamics, consist of aerodynamic force $X_{0}$, the force of friction of gases taken into the arc gap $X_{O T}$, force of friction due to forming electrode spots on the surfaces of workpiece and the electrode $X_{0 \Pi \text {. }}$. 


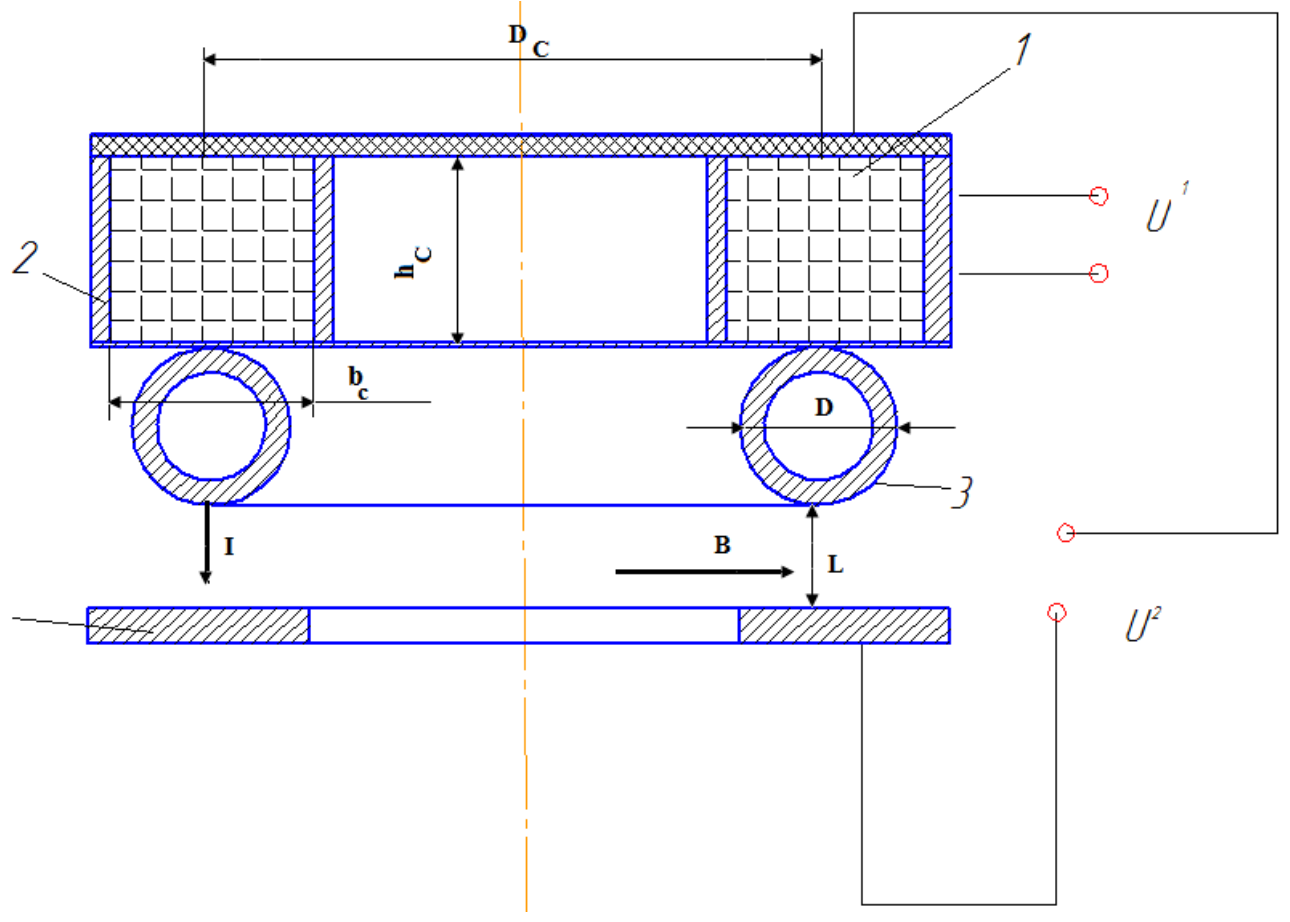

$a$

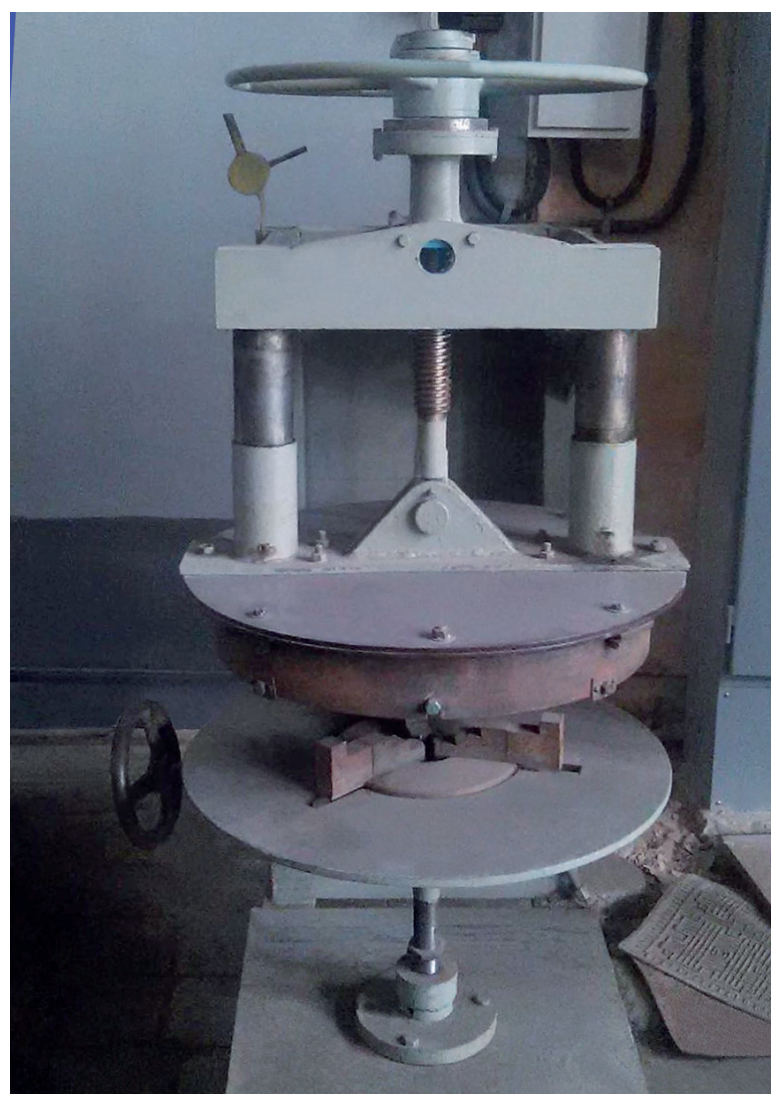

$b$

Fig. 1. Functional diagram of the test bench for investigating the kinematic parameters of arc motion in the applied stable magnetic field: $D_{c}, h_{c}, b_{c}$ are the dimensions of an inductor $(a) ; D$ is the diameter of a ring cathode; $U^{l}, U^{2}$ are power sources of the inductor and the arc respectively; $I, B, L$ are arc current, induction in the inter-electrode gap and the length of the electrode gap respectively; general view of a test bench (b) 
Roughly, it can be considered that the aerodynamic resistance force $X_{0}$ prevails in the abovementioned group. It depends on the arc motion velocity $V$, arc geometrical shape, magnetic field strength (induction), as well as the factors causing the presence of the force of resistance to gas friction (their pressure, density, flow geometry and type, ionizing potential, arc column geometry). In addition to the latter, the thermal characteristics of workpiece and electrode materials could be considered.

In general case, the integral impact of all resisting forces reduced to aerodynamic force can be shown as follows:

$$
X_{0}=K \cdot V^{n}
$$

where $K$ is a proportionality factor; $n$ is an efficiency index showing the impact of the velocity of the arc motion in the gas environment.

For arcing stage, the force $F_{1}$ is $[11,12]$ :

$$
F_{1}=245 \cdot B \cdot L \cdot V^{0.8}
$$

and does not exceed $15 \mathrm{~m} / \mathrm{sec}$.

For the stage of stationary arc motion, at the temperature of electrode spot equal to $\mathrm{T}=1100^{\circ} \mathrm{C}$, this force is:

$$
F_{1}=2.26 \cdot \rho \cdot V^{1.25} \cdot I^{0.9} \cdot L \cdot \sin \alpha,
$$

where $\rho$ is the density of gas environment; $\alpha$ is the angle of spot lagging.

The motion velocity for given values of arc current $I$ can reach $60-80 \mathrm{~m} / \mathrm{sec}$.

Since the values of abovementioned forces are conditioned by the presence of a magnetic field in the inter-electrode gap, the investigation of its intensity by the electrodynamic method with the help of the gaussmeter ИМИ-1 was conducted. It allows determining the field factors for given design of a bench tester. Measurements (Table 1) were carried out without the arc, but they enable the evaluation of their possible kinematic features by the use of analytical methods.

Table 1

\begin{tabular}{|c|c|c|c|c|c|c|c|c|c|c|c|c|c|}
\hline \multirow{2}{*}{$\mathrm{N}$} & \multirow{2}{*}{$L, \mathrm{~mm}$} & \multicolumn{12}{|c|}{ Magnetizing current $I$, A } \\
\hline & & 0,5 & 1,0 & 1,5 & 2,0 & 2,5 & 3,0 & 3,4 & 4,0 & 4,5 & 5,0 & 5,5 & 6,0 \\
\hline 1 & 0 & 100 & 180 & 260 & 340 & 400 & 480 & 550 & 620 & 720 & 780 & 840 & 880 \\
\hline 2 & 10 & 80 & 160 & 220 & 300 & 340 & 420 & 480 & 540 & 620 & 680 & 720 & 760 \\
\hline 3 & 20 & 60 & 140 & 200 & 260 & 300 & 340 & 400 & 460 & 520 & 580 & 600 & 660 \\
\hline 4 & 30 & 40 & 120 & 160 & 220 & 260 & 300 & 360 & 380 & 440 & 480 & 520 & 540 \\
\hline 5 & 40 & 20 & 100 & 140 & 200 & 220 & 240 & 300 & 320 & 380 & 400 & 440 & 460 \\
\hline 6 & 50 & 10 & 80 & 120 & 160 & 200 & 220 & 260 & 280 & 320 & 360 & 380 & 420 \\
\hline 7 & 60 & - & 60 & 100 & 120 & 180 & 180 & 220 & 240 & 280 & 300 & 320 & 340 \\
\hline 8 & 70 & - & 40 & 80 & 100 & 160 & 160 & 200 & 200 & 240 & 280 & 280 & 300 \\
\hline 9 & 80 & - & 60 & 80 & 140 & 140 & 180 & 180 & 200 & 240 & 240 & 260 & 260 \\
\hline 10 & 90 & - & - & - & - & 120 & 120 & 160 & 160 & 180 & 200 & 210 & 250 \\
\hline
\end{tabular}

Value of induction $B$ in the inter-electrode gap at different electrode gap lengths and values of inductor magnetizing current

In the table matrix, only the averaged real component of normalized records of the induction value is shown, that is, $B \cdot 10^{-5} \mathrm{~T}$; it is used further for the development and analysis of models.

The analysis of superimposed surface of the impact of magnetizing current and an arc gap on the field induction according to the data from Table 1 (Fig. 2), which are used for magnetic arc pad welding, shows that their influence as technological mode parameters is located in quite narrow range.

Previous research has ascertained that the length of welding arc should not exceed $6 \mathrm{~mm}$, and magnetizing current should not be less than 5-6 A. The latter allows the transition to a nomographic solution to the choice of technologically appropriate values of gap lengths and current (Figs. 3, 4). 


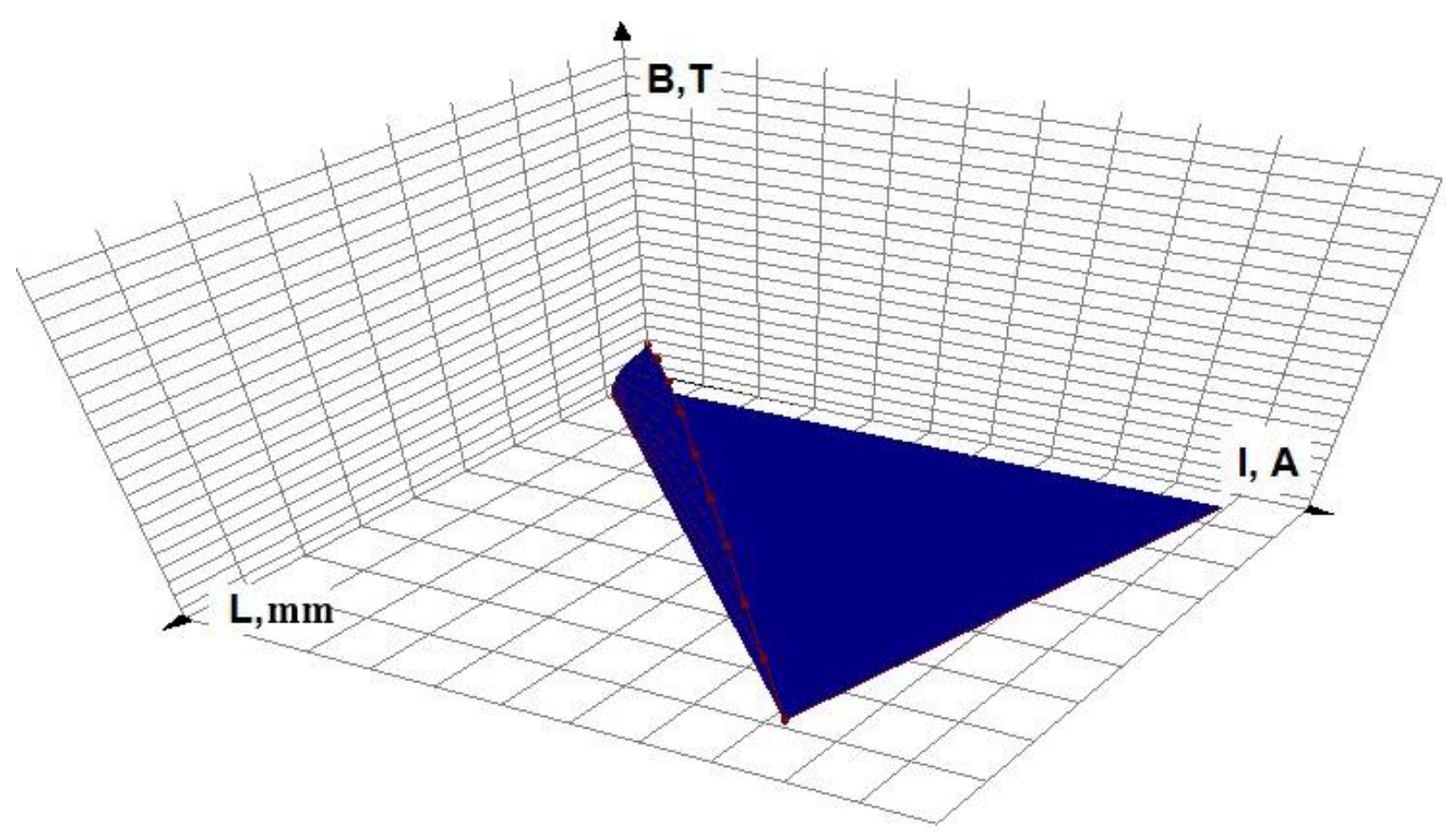

Fig. 2. Dependence of the magnetic induction $B$ on the change of the length $L$ of the electrode gap and magnetizing current I of the inductor

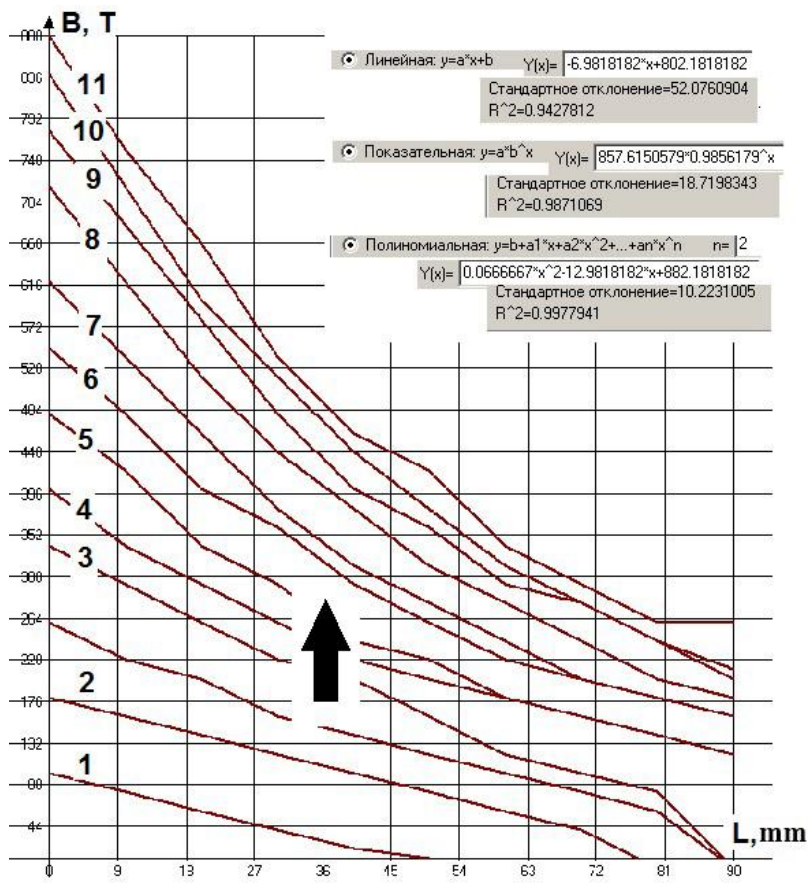

Fig. 3. Induction dependence on the length of interelectrode gap $(1-0.5 \mathrm{~A} ; 2-1.0 \mathrm{~A} ; 3 . .10$-incremental step of magnetizing current is $0.5 \mathrm{~A}$ )

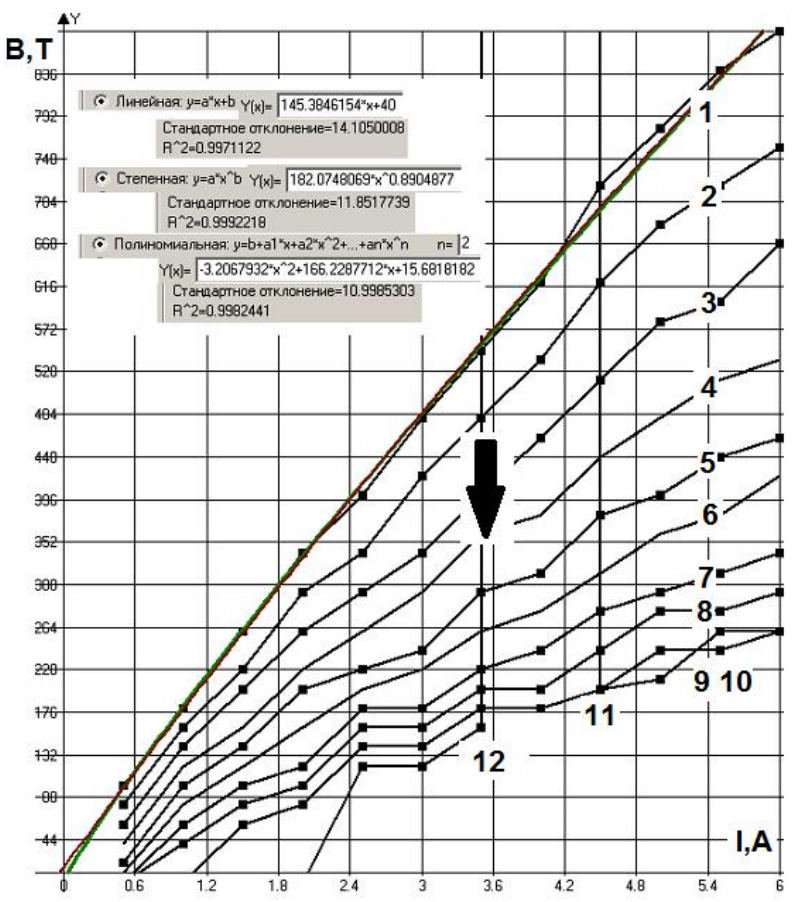

Fig. 4. Induction dependence on magnetizing current: $1 . .12$ is the length of the electrode gap; (1-10 mm, incremental step is $1 \mathrm{~mm}$ )

Although the highest reliability $(Q=0.95)$ of their description is a polynomial representation (generalized value of the determination coefficient by two projections of induction value to the field of changing the gap length and current can be found in the range $R^{2}=0.943-0.998$ ), the representation of 
nomographs as normalized standard geometrical model views (linear, exponential, demonstrative) should be considered more appropriate [13].

Accordingly, if the induction value is optimized at the expense of the length of arc gap, the demonstrative model is a functional one for a given value of magnetizing inductor current:

$$
B=857.615 \cdot 0.986^{L} ; y=a \cdot b^{x} ; x=L ; R^{2}=0.987 .
$$

At the same time, for the process of arc pad welding with a stable arc gap, when the induction is specified only by the magnetizing current, two nomograph model analogs (Figs. 5,6 ) are statistically actual:

linear model:

$$
B=145.384 \cdot I+40 ; R^{2}=0.997
$$

and exponential one:

$$
B=182.074 \cdot I^{0.89} ; Y=a \cdot x^{b} ; \quad R^{2}=0.999 \text {. }
$$

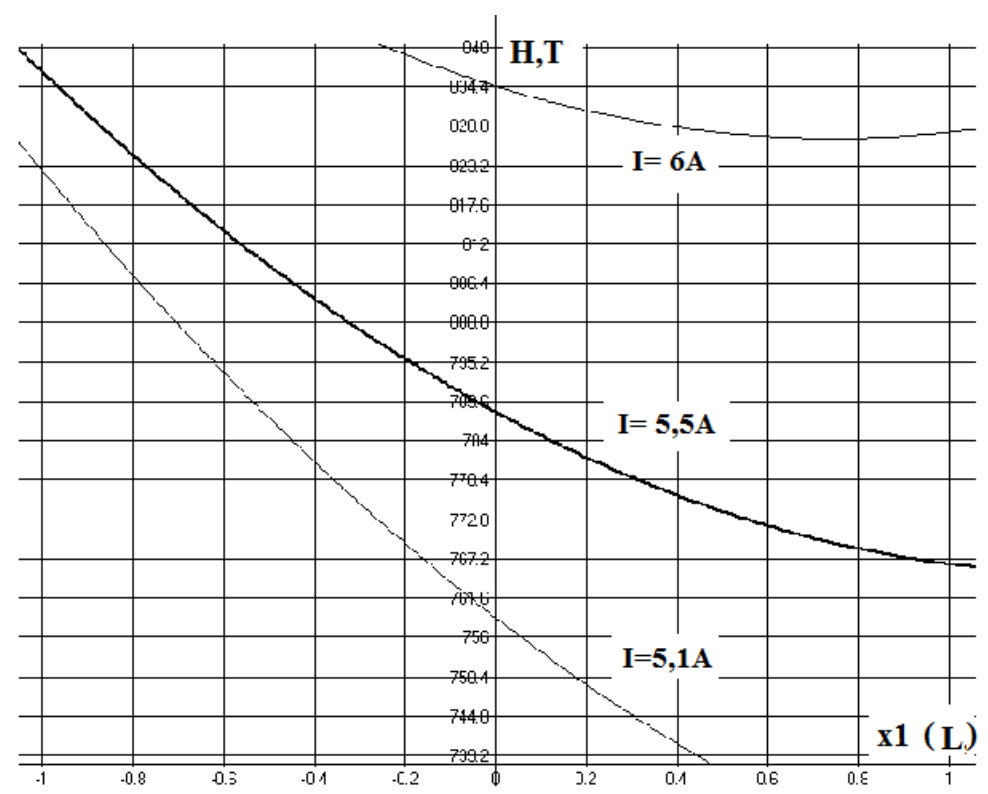

Fig. 5. Model representation of arc gap length impact on the induction value in it within the range of boundary values of magnetizing current

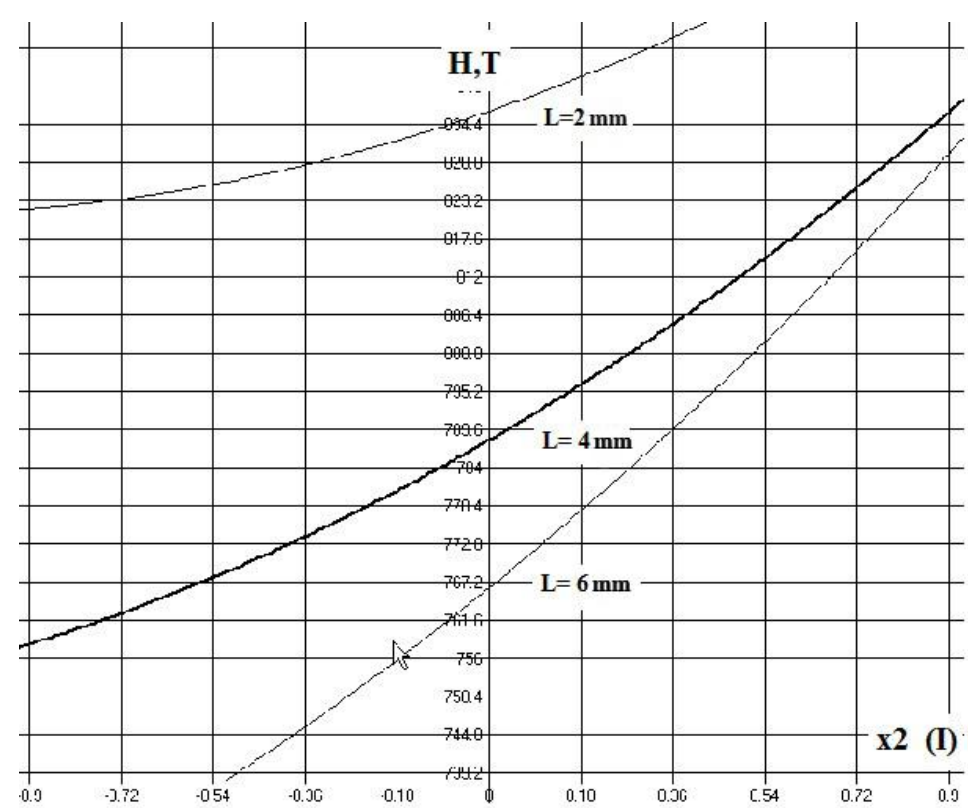

Fig. 6. Model representation of impact of magnetizing current value on the induction value within the range of boundary values of the arc gap 
A considerable tolerable limit of the induction value in the inter-electrode gap at pre-set confidence probability according to (6), (7) requires conducting some separate optimization experiment for the strict determinations of settings for pad welding with magnetic arc. These settings are the technologically suitable arc gap and the value of magnetizing current of the inductor for providing the field induction enough for the arc kinematic controlled by the field.

Accordingly, for optimal choice of model nomographic solutions and the description of the parameters of the arc gap and magnetizing current which provide the technologically suitable induction, an experiment was conducted according to the matrix of simplex-summarized $\mathrm{C}-\mathrm{C}_{2}$ design (Table 2) [14].

Table 2

Matrix of $C-C_{2}$ design and parameters of regressive model of $B=f(L, I)$ kind

\begin{tabular}{|c|c|c|c|c|c|c|c|c|}
\hline $\mathrm{N}$ & $X 1$ & $X 2$ & $Y_{i}^{\prime}, Y_{i}^{\prime \prime}$ & $\bar{Y}$ & $\hat{Y}$ & $\begin{array}{c}\text { Model } \\
\text { coefficients }\end{array}$ & $\begin{array}{c}\text { Mean- } \\
\text { square } \\
\text { deviations }\end{array}$ & Parameters of model adequacy \\
\hline 1 & -1 & 0 & 860.840 & 850 & 836.4 & \multirow{7}{*}{$\begin{aligned} b_{0} & =788.1 \\
b_{1} & =-34.965 \\
b_{2} & =43.457 \\
b_{11} & =13.314 \\
b_{22} & =11.247 \\
b_{12} & =17.4\end{aligned}$} & \multirow{7}{*}{$\begin{aligned} S_{e} & =11.34 \\
S_{b 0} & =11.34 \\
S_{b 1} & =6.55 \\
S_{b 2} & =6.55 \\
S_{b 11} & =13.89 \\
S_{b 22} & =13.89 \\
S_{b 12} & =13.1\end{aligned}$} & \multirow{7}{*}{$\begin{array}{c}\text { Cochran's criterion } \\
G_{\alpha=0.05 ; \mathrm{fl}=1, \mathrm{f} 2=7}=0.441 \leq G_{\mathrm{T}}=0.7271 \\
\text { Adequacy dispersion } \\
S_{\text {ad }}^{2}=623.475 ; n=7 ; k=2 \\
\text { Fisher's test } \\
F=4.848 \leq F_{T}=6.03_{\alpha=0.05, \mathrm{fl}=4, \mathrm{f} 2=7}\end{array}$} \\
\hline 2 & 1 & 0 & 765.755 & 760 & 801.4 & & & \\
\hline 3 & 0.5 & 0.87 & 810.850 & 830 & 823 & & & \\
\hline 4 & 0.5 & -0.87 & 735.745 & 740 & 738 & & & \\
\hline 5 & -0.5 & 0.87 & 815.845 & 830 & 849 & & & \\
\hline 6 & -0.5 & -0.87 & 765.775 & 770 & 786.3 & & & \\
\hline 7 & 0 & 0 & 800.820 & 810 & 788.1 & & & \\
\hline
\end{tabular}

Table 3

Parameters assumed for calculations

\begin{tabular}{|c|c|c|c|}
\hline$L, \mathrm{~mm}$ & $X 1$ & $I, \mathrm{~A}$ & $X 2$ \\
\hline 2 & -1 & 0 & 5.5 \\
\hline 6 & 1 & 0.87 & 5.94 \\
\hline 5 & 0.5 & -0.87 & 5.06 \\
\hline 3 & -0.5 & - & - \\
\hline 4 & 0 & - & - \\
\hline
\end{tabular}

The calculation of regression indices is conducted by an algorithm:

$$
\begin{gathered}
b_{0}=T_{1} \cdot \sum Y_{i}-T_{2} \cdot \sum_{K} X_{i}^{2} Y_{i} ; \\
b_{i}=T_{3} \cdot \sum X_{i} \cdot Y_{i} ; \\
b_{i i}=T_{4} \cdot \sum X_{i}^{2} \cdot Y_{i}+T_{5} \cdot \sum \sum_{K} X_{i}^{2} \cdot Y_{i}-T_{7} \cdot \sum Y_{i} ; \\
b_{i j}=T_{6} \cdot \sum X_{i} \cdot X_{j} \cdot Y_{i} ; \\
T_{1}=1 ; T_{2}=1 ; T_{3}=0.333 ; T_{4}=0.6667 ; T_{5}=0.83333 ; T_{6}=1.3333 ; T_{7}=1 .
\end{gathered}
$$


The error of the experiment is:

$$
S_{e}^{2}=\sqrt{\frac{\sum_{m}^{n_{m}} \sum_{m}\left(Y_{i}-\bar{Y}\right)^{2} \cdot\left(m_{i}-1\right)}{n_{m} \cdot \sum\left(m_{i}-1\right)}},
$$

where $n_{m}$ is the number of experiments in the planning matrix with experiment duplication; $m_{i}$ is the number of duplets in every experiment.

Mean-square deviations of determining the regression indices are:

$$
S_{b_{o 0}}=S_{e} ; S_{b_{i}}=T_{8} \cdot S_{e} ; S_{b_{i i}}=T_{9} \cdot S_{e} ; S_{b_{i j}}=T_{10} \cdot S_{e},
$$

where $T_{8}=0.57735 ; T_{9}=1.22474 ; T_{10}=1.15447$.

Cochran's criterion of dispersion homogeneity is:

$$
G=\frac{S_{\max }^{2}}{\sum S_{i}^{2}} \leq G_{T a b l} ; \alpha, f_{1}, f_{2},
$$

where $S_{\max }^{2}$ is maximum dispersion (according to the matrix of experiments) noticed in the $i$-th experiment.

Adequacy dispersion is:

$$
S_{a d}^{2}=\frac{\sum\left(\bar{Y}_{i}-\hat{Y}_{i}\right)^{2}}{n-k-1}
$$

where $\hat{Y}_{i}$ is a model value of the real component of the normalized representation of induction value in the inter-electrode gap; $n$ is the number of experiments according to the experiment matrix of design; $k$ is the number of variable factors in the regressive model.

Therefore, the regressive model description of the induction changes in the arc gap at the variations of values of the arc gap and magnetizing current (within the range of optimizing experimentation) can be represented as follows:

$$
\begin{gathered}
\hat{Y}=b_{0}+b_{1} \cdot X 1+b_{2} \cdot X 2+b_{11} \cdot X 1^{2}+b_{22} \cdot X 2^{2}+b_{12} \cdot X 1 \cdot X 2 \\
\hat{Y}=788.1-34.965 \cdot X 1+43.457 \cdot X 2+13.314 \cdot X 1^{2}+11.247 \cdot X 2^{2}+17.4 \cdot X 1 \cdot X 2 .
\end{gathered}
$$

The investigation of model extremum (13) shows the acceptable induction value of $850 \cdot 10^{-5} \mathrm{~T}$ for the length of the electrode gap of $4 \mathrm{~mm}$ and inductor magnetizing current of $6 \mathrm{~A}$.

Additional graphical (Figs. 7, 8) and analytical analysis of a model (13) provides evidence that a) maximum induction at the level of $880 \cdot 10^{-5} \mathrm{~T}$ and according to given design of the inductor can be provided at the length of the arc gap not exceeding $2 \mathrm{~mm}$ and magnetizing current being no less than $6 \mathrm{~A}$; the last padding limited by technological value of pad welding current and appropriate length of the arc column at a given shielding gas; b) curvature of respond surface taking into account the real length of arc column determines the range of induction variations at given magnetizing current from 800 to $880 \cdot 10^{-5} \mathrm{~T}$; c) according to weighting factors evaluated by the coefficients of model regressors (13), the most influential factors are the linear coefficients, which allow quite flexible changing of kinematic properties of the arc moved by the magnetic field (by the factors about mean $-44.4 \%$ and $+55.1 \%$ respectively), but the depth of adjusting is rather limited by the influence of square effects of each technological setting (17\% and $14.3 \%$ respectively, which positively affect the induction increment) and joint influence of two factors evaluated by the interaction effect $(22.6 \%)$ practically limits the depth of mode adjustment by the length of arc gap.

Therefore, the unambiguous conclusion can be drawn that the main technological setting of arc kinematics at the given pad weld current and corresponding arc gap in the given shielding gas environment is the inductor magnetizing current, or, indirectly, its design. 
On the basis of predicted values of induction in the arc gap, it is possible to analytically evaluate the arc kinematics by the velocity of its motion as current conductor in the static magnetic field with maximum induction value provided either by inductor design, or really formed length of the arc column at given pad current.

The calculations are based on the aerodynamic motion of the body in motionless gas environment with following assumptions: a) the arc is a conditionally rigid cylindrical current conductor with midsection radius up to $3.5 \mathrm{~mm}$ (by the calculated values of pad weld current); b) the inertia of forming and moving the arc spots is sufficiently small and can be neglected in changes of arc column geometry (arc column bending); c) arc motion occurs in homogeneous shielding gas environment (argon) with pressure of 0.11 bar and density of $11 \mathrm{~g} / \mathrm{m}^{3}$ at the averaged temperature of arc column and electrode spots; d) the arc motion velocity is steady, the areas of the ignition and development of arc discharge and acceleration are neglected (in real conditions the arc is ignited by the additional discharge in the previously applied magnetic field); e) while moving steadily, the arc is in the balance of magnetomotive force (1) and aerodynamic force of the gas environment resistance to the arc column motion, which is [15]:

$$
X_{0}=c_{X 0} \cdot \rho \cdot S \cdot \frac{v^{2}}{2 \cdot g},
$$

where $c_{X 0}$ is a dimensionless aerodynamic coefficient of frontal resistance connected with the Reynolds similarity criterion. Taking into account the resistance of the cylindric shape of arc column (90\%) and resistance of viscous friction of gases $(10 \%)$, its value can be considered equal to $1.18 ; \rho$ is the argon density and equals $11 \mathrm{~g} / \mathrm{m}^{3}$ at the arc column temperature of $6000 \mathrm{~K} ; S$ is the characteristic midsection area of $7 \cdot 10^{-6} \mathrm{~m}^{2} ; v$ is a velocity of arc motion; $g$ is a gravitation constant.

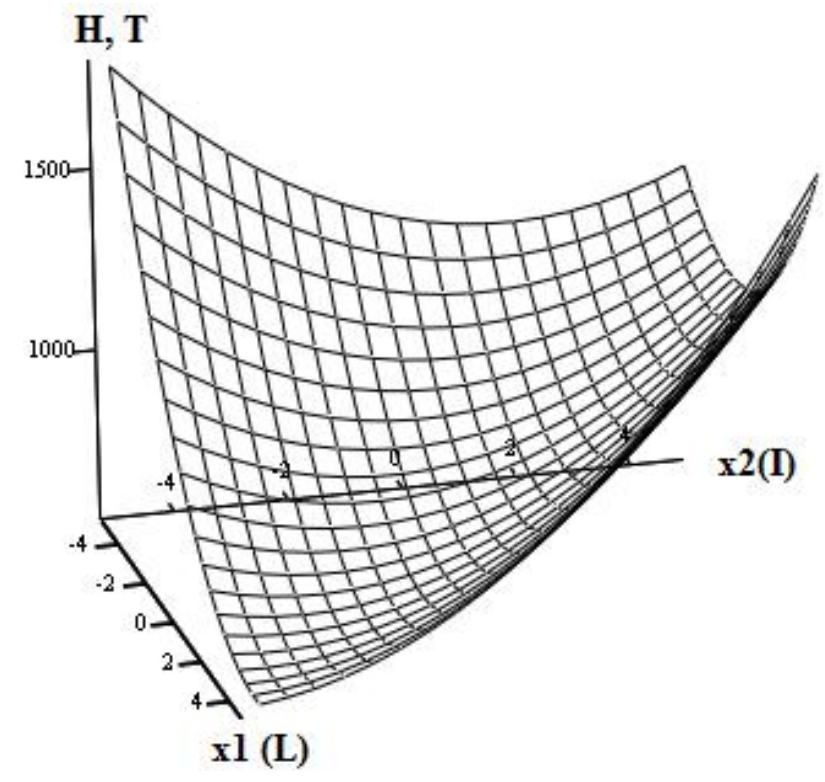

Fig. 7. The surface of the respond of evaluation of the value of magnetic induction in the inter-electrode gap at the interaction of technological modes of the arc pad welding: arc length (x1) and magnetizing current ( $x 2)$

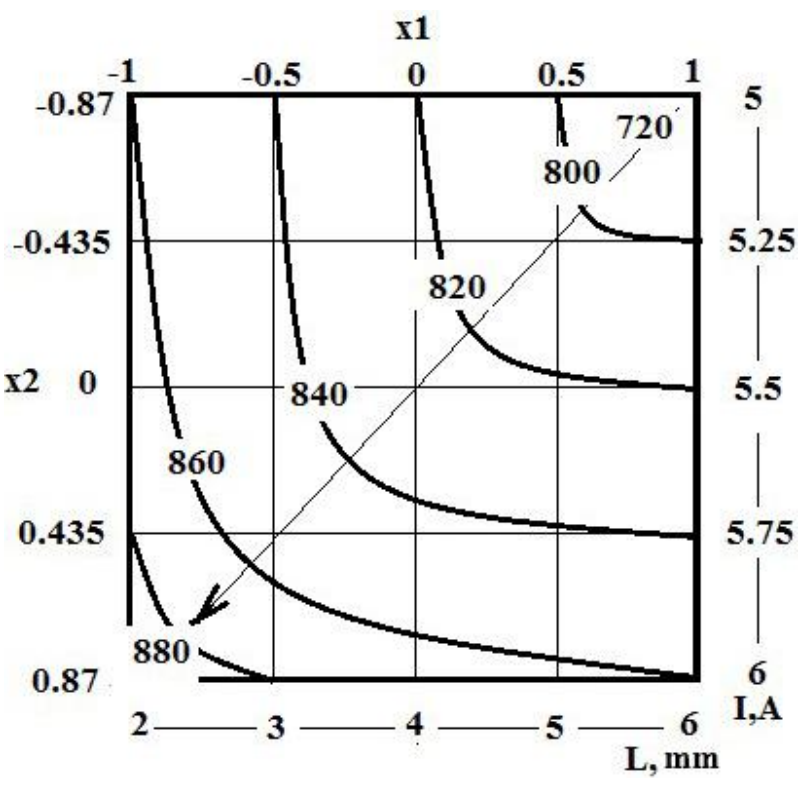

Fig. 8. Changes of induction of magnetic field at the variations of the length of arc gap and magnetizing current

At high arc motion velocity, the resistance force is:

$$
X_{0}=c_{X 0} \cdot \rho \cdot S \cdot \frac{v^{2}}{2} .
$$


According to Stokes's law for small bodies and velocities, the resistance force is:

$$
X_{0}=k \cdot \eta \cdot L \cdot v,
$$

where $k$ is the shape coefficient which can be equal to $c_{X 0} ; \eta$ is a dynamic viscosity; $L$ is a midsection.

Dynamic viscosity of argon at welding temperature is:

$$
\eta=\eta_{0} \cdot \frac{T_{0}+c}{T+c} \cdot\left(\frac{T}{T_{0}}\right)^{3 / 2}=82.82 \mathrm{~Pa},
$$

where $c=111 \mathrm{~K}$ is the Sutherland constant; $T_{0}$ is gas temperature at normal conditions $(300 \mathrm{~K})$; $T=5700 \mathrm{~K}$ is working temperature of the gas.

Then, for (17) and above mention conditions at the stage of arc development, the resistance force equals to $0,684 \cdot \mathrm{V}$. The calculated value of arc motion velocity is equal to about $5 \mathrm{~m} / \mathrm{sec}$ per motion unit (m) of the motion trajectory, that is, $23.4-24.1 \mathrm{~m}^{2} / \mathrm{sec}$, according to the joint solution of (1) and (15) and at steady motion. The steady arc motion was noticed here, which is accompanied by the effective repeated surface weld without damaging the surface of a ring electrode by the thermal impact of the arc cathode.

\section{Conclusions}

The proposed design of the bench tester is relevant to the geometric features of renovated workpiece and enables using the effective repeated thermal pad cycle per unit of the surface by the rotating arc in the stable magnetic field. Settings of the magnetically operated arc, which provide the necessary value of field induction in the inter-electrode gap, can be determined either by nomograph solution, or by the strict statistic models. The influence of the length of the inter-electrode gap on the choice of the induction value is limited by technologically suitable pad current and corresponding length of the arc column. The main setting and controlling parameter of the magnetic field mode is the inductor magnetizing current. The force of the resistance to arc motion at the stage of its development and at the stage of steady motion is directly proportional to the value of pad current. Calculated values of the velocity of arc motion at given values of the pad current are in the range relevant to its steady motion and provide the processes of anode melting without thermal damaging the ring cathode.

\section{References}

[1] S. I. Kuchuk-Yatsenko, et al., "Magnetically-impelled arc butt welding of pipes of steel X70", Australasion welding journal, vol. 55, Second Quarter, pp. 20-22, 2010.

[2] T. Sato, et al., "An experimental study of rotational behaviour of the arc during magnetically impelled arc butt welding", Journal Welding International, vol. 5, pp. 5-10, 1991.

[3] V. S. Kachynskyi, et al., "Tehnologija i oborudovanie dlja pressovoj svarki magnitoupravljaemoj dugoj nepovorotnyh stykov trub malogo diametra v montazhnyh i stacionarnyh uslovijah" [“Technology and equipment for press-welding of a magneto-controlled arc of non-rotary joints of small diameter pipes in installation and stationary conditions"], Avtomaticheskaja svarka [Automatic welding], no. 6, pp. 33-38, 2016. [in Russian].

[4] O. P. Bondarenko, et al., "Avtomatychne keruvannia elektrozvariuvalnymy protsesamy i ustanovkamy" [ "Automatic control of welding processes and installations"], Kyiv, Ukraine: Vyshcha shkola Publ., 391 p., 1994. [in Ukrainian].

[5] V. S. Kachinskiy, et al., "Magnetically Impelled Arc Butt Welding of Hollow and Solid Parts", Welding in the World, Vol. 46, pp. 49-56, 2002.

[6] V. N. Volchenko, et al., "Teorija svarochnyh processov" ["Theory of welding processes"], Moscow, Russia: Vysshaja shkola Publ., 559 p., 1988. [in Russian].

[7] V. Biloborodchenko, "Applied Model of Assessment of Intensity of the Stressed Deformed State of Pipelines by Evaluation of Magnetic Anisotropy of Coercive Forces. Part 1", Ukrainian Journal of Mechanical Engineering and Materials Science, vol. 3, no. 1, pp. 27-36, 2017.

[8] F. J. Ganovski, "The magnetarc welding process", Welding Metal Fabrication, no. 5, pp. 206-213, 1974. 
[9] K. Takagi and F. Aracida, "Magnetically Impelled Arc Butt Welding of gas pipeline", Metal Construction, no. 10 , pp. 542-548, 1982.

[10] S. V. Arungalai, et al., "Feasibility of Magnetically Impelled Arc Butt (MIAB) Welding of HighThickness Tubes for Pressure Parts", Journal Materials and Manufacturing Processes, vol. 27, pp. 573-579, 2012.

[11] I. P. Vasenko and E. V. Lebsak, "Vlijanie elektricheskogo i magnitnogo polja na formu dugi i polozhenie ee gorenija v podogrevatele koaksial'nogo tipa" ["The influence of the electric and magnetic fields on the shape of the arc and the position of its combustion in a coaxial type heater"], Uchenye zapiski CAGI [Scientific notes of TsAGI], vol. 31, issue 3-4, pp. 104-118, 2000. [in Russian].

[12] V. N. Volchenko, "Svarka i svarivaemye materialy. Spravochnik" ["Welding and welded materials. Handbook"], Moscow, Russia: Metallurgija Publ., 1991. [in Russian].

[13] I. M. Vinogradova, "Matematicheskaja jenciklopedija" ["Mathematical Encyclopedia"], Moscow, Russia: Sovetskaja jenciklopedija Publ., 1215 p., 1984. [in Russian].

[14] V. Z. Brodskij, et al., "Tablicy planov jeksperimenta dlja faktornyh i polinomial'nyh modelej" ["Tables of experiment plans for factorial and polynomial models"], Moscow, Russia: Metallurgija Publ., 752 p., 1982. [in Russian].

[15] A. D. Girgidov, "O lobovom soprotivlenii cilindra" ["On the drag of a cylinder"], Inzhenerno-stroitel'nyj zhurnal [Engineering and construction Journal], no. 1, pp. 9-11, 2011. [in Russian]. 